\title{
OCCUPATIONAL DISEASES: GENERAL CHARACTERISTICS, PECULIARITIES AND CHARACTER OF THE SYSTEM OF HEALTH SERVICE AND FINANCIAL COVER OF THE ACTIVITY IN OCCUPATIONAL DISEASES MEDICAL AREA IN BULGARIA AND IN SOME CENTRAL EUROPEAN COUNTRIES
}

\author{
Petrova E. \\ Centre on Occupational Diseases, Medical University, Clinic on Occupational Diseases, \\ Medical University Saint Ivan Rilski, Sofia, Bulgaria
}

Reviewed by: Assoc. Prof. St. Popova

\begin{abstract}
The Objects of the study were different systems of service and financial cover for the diagnosics, prophylactic activities and expertise of occupational diseases (ODs) in Bulgaria as well as in some Central European countries. The Aim of the study was to investigate different systems of a service and a financial cover for the medical activities on ODs in Bulgaria and in some Central European countries, and to find a decision for the existing problems in Bulgaria. Materials: The information from the existing legislative acts on ODs in Bulgaria, as well as the information from the Central European countries acts in Internet Web pages of the WHO collaborating centers on occupational, centers of public health as well as clinics on ODS was studied. Discussion: There is well organized and structured system on ODs in Bulgaria, but there are some problems as well. With regard to this it is necessary to ensure a different financial cover for medical activity concern diagnostics and treatment on ODs. It is compulsory to be improved the qualification on occupational diseases of specialists on "ODs", specialists on "occupational medicine", as well as general practitioners and other clinicians in our country.
\end{abstract}

Key words: occupational diseases, management, diagnostics, expertise, prophylaxis, treatment, financial cover

\section{INTRODUCTION}

The diseases, related to people work activities are divided in two groups: occupational injuries and occupational diseases (ODs). The occupational injuries (OIs) are acute incidents of the human organism, appeared during the work time, on way to work or during back to home. OIs appear in extreme situations (trauma, acute poisoning etc). The causes and the cause/effects relationship in cases with OIs are clear and sometimes they are followed by temporary disability to work. It is possible to appear a permanent disability in part of the cases with OI. Each new case with OI in Bulgaria has recognized by issuing of a specific document, so called "occupational injury act". I contrast to the occupational injuries (OIs). The ODs are chronic damages with unknown cause/effect relationship, so it has to be proven. The definition of ODs according to legislative acts

Address for correspondence:

E. Petrova, DSC, Centre on Occupational Diseases; University Hospital Saint Ivan Rilski 15 Bull. Akademic Ivan Geshov

1431 Sofia

e-mail:mdepetrova@yahoo.com in Bulgaria is: The ODs are a group of diseases which appear fully or predominantly due to the harmful factors of work environmental factors and due to working process. The occupational diseases are an important part of the public and social health in each country. The ODs are multi-profile and depending to the peculiarity and the origin of the etiological factors, and they influence different organs and systems in the human organism. There are a lot of papers and decrees on ODs service and about financial cover in this field in different European countries, including in Bulgaria (1-9), but the problems were not solved.

The Aim of the study was to investigate different systems of service and a financial cover for the medical activities on ODs in Bulgaria and in some Central European countries, and to find a decision for the existing problems in Bulgaria. Materials The information from the existing legislative acts on ODs in Bulgaria, as well as the information from the Central European countries acts in Internet Web pages of the WHO collaborating centers on occupational, centers of public health as well as clinics on ODs was studied. 


\section{RESULTS}

\section{Analysis of system and the service activities on occupational diseases in Bulgaria}

The activities on ODs are narrowly related to existing Lists of ODs that are specific for each country. The Lists on occupational diseases (LODS) are related to the peculiarities and technological levels of the industrial branches in each country and to the quality of preventive measures. Bulgaria disposes its own LODS. In 2005 year according to the Project of Fund "Work Conditions" in Ministry of Labour and Social Politic in Bulgaria was created LODS according to etiological principle, conformable to $\mathrm{EC}$ recommendations 2003. Bulgarian LODS corresponds to lists on ODs of EC countries. We expect publication of LODS and it's using as an official legislative act in Bulgaria.

There are several levels and service structures on ODs in Bulgaria:

1. First level - prophylaxis and measurement of risk factors and risk/effect relationship on ODs served by Occupational medicine service units (OMSU), and by special laboratories for measurement of work place risk factors (LWPRF)

2. Second level - diagnostics and treatment of ODs, performed in the clinics on ODs in five university hospitals in Bulgaria

3. Third level - assessment of risk factors and risk for ODs before expertise on ODs, which is performed in Department on OIs and ODs in the National Insurance Institute in Bulgaria

4. Fourth level - expertise of ODs and for work ability is performed in five Regional Expert Commissions on ODs

5. Fifth level - registration, statistics every year account of the incidence on ODs, performed in National Register on occupational diseases, performed till now in National Centre on Public Health Safety. The procedures for announcement, registration, confirmation, acceptance and appeal of ODS are arranged by special Decree No 33, published in Official State Newspaper on 4 April 2001yr.

A financial cover of medical service on ODs in Bulgaria is different at different levels:

1. The medical activities of Occupational medicine service units (OMSU) in Bulgaria are covered directly by the employers.

2. The medical activities of the Expert commissions on occupational diseases are financially covered by the budget of the Ministry of Health.

3. The diagnostics and the treatment on occupational diseases are covered occasionally by existing clinical pathways of the National Health Insurance Fund.

4. There is a new Decree No8/2007 arranging special financial cover for diagnostics on ODs, which will be leaved to the clinics on occupational diseases by Fund "Work Conditions" in Ministry of Labour and Social Politic in Bulgaria.

\section{Systems of services on ODs in some Central European countries}

There are several institutes with clinics on ODs in Poland. There is WHO collaborating Centre with Nofer Institute on Occupational Medicine with Clinic on ODs in Lodz. Nofer Institute on Occupational Medicine performs a diagnostics, an expertise and a scientific activity in ODs area. Nofer Institute performs a typical for the region wide range scientific activity by projects in chemical and textile industry (occupational poisonings and allergies). There is Institute of dust ODs (a.m. coal workers' pneumoconiosis, asbestosis, chronic obstructive pulmonary disease (COPD) etc in Sosnovets, Poland.

There is Institute on Occupational Medicine in Medical Academy in Latvia. At the territory of institute works:

1. department on occupational and radiation medicine

2. outpatient clinic

3. Latvian Register on ODs

4. laboratory on heavy metals investigation.

The hospital structure of the Institute on Occupational and Environmental Health is situated in "Stradina Hospital" in Riga, where are performed a diagnostics of the ODs, as well as clinical investigations, and studies of the risk factors at the work places. The Commission of ODs in Latvia is based in the Institute on Occupational and Environmental Health, and the specialists on ODs are licensed and included in special List of experts on ODs. The Commission on ODs serves all Latvia. Expertise is performed in the next order:

1. In case of observation for ODs the GP sends a notification.

2. A control of the risk factors is performed by labour inspectors.

3. The expertise on ODs is performed by the commission which included different specialists: head occupational physician included in national List of the experts) + neurologist + specialist on allergy + specialist on occupational hygiene.

4. In case of accepted ODs the patient has to be directed to commission for work ability expertise.

5. Recently the expertise of occupational character of the diseases is assessed parallel with an expertise of work ability.

There are 37 specialists on occupational medicine, who work in different structures and areas of Lithuania WHO Collaborating Center on Occupational Medicine. They work in the next areas and structures:

1. Occupational health and it's service as well as occupational hygiene, occupational medicine, studies, standard network, programs, in occupational health area, harmonizing of the Lithuania legislation with the European directives, education, work with National Register on ODs, distribution of information, ODS expertise.

2. The Research Department creates criteria for expertise, as well as for laboratory activities, incl. investigations of chemical factors, physical factors, and the activity of National Register on ODs. 
Occupational diseases: general characteristics, peculiarities and character ...

There is Center on Occupational Hygiene and ODs in the

Czech Republic with the next system and structures:

1 There is a group on ODs, leading the Czech National Register on ODs, realizing long lasting monitoring on ODs and accounting their structure.

2. The group on ODs works parallel with the Clinic on ODs in First Medical Faculty in the Carl's University in Prague.

3. The group on ODs collaborates with the Medical University for realizing the medical postgraduate education on ODs.

4. There are outpatient clinics on ODs, doing the diagnostics of ODs.

The group on ODs in Czech Republic performs clinical, as well as experimental, and epidemiological studies with accent toward:

1. occupational lung diseases (Pulmonary fibrosis asbestosis, silicosis) and allergic respiratory diseases (asthma)

2. functional respiratory diagnostics with new trends and criteria

3. neurologicval ODs with accent to neurological intoxications due to organic solvents and metals' poisonings

4. muscle skeletal disorders due to vibrations and heavy physical work and

5. applicabillity of electro-physiological diagnostic methods ODs as well as assessment of their utilization for early detection, and for improvement of diagnostics of ODs.

Occupational stress and work ability in persons working at non-industrial work places.

There is luck of specialist on ODs, as well as formal leading of the medical prophylactic screenings surveillance, and late detection of the ODs in Estonia during the period of political and economical transition. At the same time, in a big part of patients there are two, three or more registered ODs. There is Institute on Health Safety and Institute on Occupational Medicine in Slovenia.

There is Federal Institute on Health Safety with similar institutes in Berlin, Dresden, and Dortmund, Bremen etc in Germany. The structure on work related diseases and occupational diseases are based at the first level in the institute in Berlin.

\section{Financial cover on ODs in Central European countries}

A financial project for insurance at the work place, covered by EU, is performed in Slovenia. A new insurance company financing workers' health, including all measures for prevention and promotion, as well as the expenses on OIs and ODs was created in Slovenia.

The insurance in Austria is realized by insurance company AUVA. Austrian social insurance takes care for 180000 damaged and for OIs and ODs. AUVA pays about 72000 compensations for impaired by OIs and ODs and for their families. The legislative obligations of the insurance institution embrace:
1. prophylaxis of OI and ODs

2. occupational medicine service

3. OIs and ODs compensations

4. posttraumatic treatment

5. rehabilitation

6. scientific studies in this field etc.

The legal insurance for incidences was created in Germany a hundred years ago, created as German social insurance system, invented by German chancellor Otto von Bismarck. He had invented social insurance legislation in Germany in 19 Century. The compulsory public insurance in Germany covers:

1. risks and diseases

2. uarantees incomes for advanced in years

3. Insures guarantees on occupational and general work disability

4. takes a responsibility for $\mathrm{OI}$ as well as

5. takes the subsequently by OIs

6. pays for incidents in transport and for ODs,

7. pays expenses in case of long lasting service.

The first legislative responsibility in Germany is prevention against OIs and ODs and elimination of the occupational risk In case of injury the company insures the patient and his (her) relatives. Each company belongs to definite branch, which is responsible for the corresponding industry. The taxes of the company are calculated due to all payments of the companies on the basis of the risk category. The insurance cover is lived for OIs, incidents due to transport, as well as for ODs. The medical service on ODs is performed according to the specific German List on ODs.

\section{CONCLUSIONS}

Bulgaria has a well structured system of service on ODs, but there are some defects:

1. Luck of collaboration between the units, served ODs.

2. Luck of enough control under activity of OMSU and laboratories, measuring the harmful risk factors, as well as non-objective assessment for the risk of ODs.

3. There isn't an answer on the question for the harmful effects on the human organism due to exposure on the occupational factors in industrial branches in Bulgaria during the last two decades. The latent prevalence increases in Bulgaria during the last two decades.

4. There are problems in the quality of the expertise on ODs, due to low level of qualification of the experts in the Regional Expert Commissions on ODs.

5. There is luck of realistic information on the incidence and prevalence on ODs in Bulgaria.

6. The financial problem in the prophylactic, diagnostic, treatment, scientific and education activity on ODS is not solved adequately.

The decision of the problems on occupational diseases could be solved after:

1. soon publish of the new List on ODS, performed by experts in the leading Clinic on ODs in Sofia parallel with experts in National Insurance Institute in Bulgaria 
2. invention a new administrative document base for investigation, registration, and notification on ODs in Bulgaria

3. publish of new Decree for investigation, registration, and notification on ODs in Bulgaria, prepared by expert in Clinic on occupational diseases in Sofia parallel with experts in National Insurance Institute in Bulgaria

4. invention a new effective mechanisms for control under the activity of the OMSU and laboratories measuring the harmful risk factors at different work places in Bulgarian

5. improvement of the collaborations between OMSU, clinics on occupational diseases, GP and Regional Expert Commissions on ODs

6. improvement of the diagnostics on ODs by adequate apply special financing cover for the diagnostics on ODs existing in Legislative act published in December 2007

7. a concentration of the expertise activity in one-two specialized expert commissions on ODS in Bulgaria

8. invention of new models of education of medical specialists in field on ODs

9. attraction of young specialists toward ODs area by including parts of the ODs in the different courses of specialization.

\section{REFERENCES}

1. WHO Collaborating centers. WHO Sites. Internet, 2005.
2. Decree No3 for preliminary and periodical medical survey of workers published in Official State Newspaper No4/1987, 102/1994 etc.

3. Decree No80/29.03.2001 for the List on Occupational diseases.

4. Decree No 79/29.03.2001г. for investigation, registration, and notification on occupational diseases published Official State Newspaper No33/04.04.2001.

5. Decree for medical expertise of the work ability, published in Official State Newspaper No99/ 31.05.2005., No 47/ 7.06.2005.

6. Decree No3 for the conditions, order and activity of the Occupational medicine service units published in Official State Newspaper No14/ 12.02.2008.

7. Petrova E, Kostova V, Petkova V, Kuneva T, Apostolova D, Stoineva Z1, Kuzmov Sh, Petrova P, Nikolov A, Mateev M. "Project for improvement of the national practice on signalizing, investigation, conformation and registration of the occupational diseases and their appliance toward European directions for development in this field, accepted and approved in Fund Working Conditions, Ministry of Labour and Social Politics in 2005y.

8. Low of the budget of the state public insurance published in Official State Newspaper No 113/28.12.2007.

9. Decree No8/26.11.2007 for the conditions and the order of financial cover for the diagnostics on occupational diseases by Fund "Working Conditions", published in Official State Newspaper No103/13.12.2007. 